\title{
Improving the Repair Planning System for Min- ing Equipment on the Basis of Non-destructive Evaluation Data
}

\author{
Michael Drygin ${ }^{1 *}$, and Nicholas Kuryshkin ${ }^{1}$ \\ ${ }^{1}$ T. F. Gorbachev Kuzbass State Technical University, 28 Vesenija str., Kemerovo 650000, Russia
}

\begin{abstract}
The article tells about forming a new concept of scheduled preventive repair system of the equipment at coal mining enterprises, based on the use of modern non-destructive evaluation methods. The approach to the solution for this task is based on the system-oriented analysis of the regulatory documentation, non-destructive evaluation methods and means, experimental studies with compilation of statistics and subsequent graphoanalytical analysis. The main result of the work is a feasible explanation of using non-destructive evaluation methods within the current scheduled preventive repair system, their high efficiency and the potential of gradual transition to condition-based maintenance. In practice wide use of nondestructive evaluation means will allow to reduce significantly the number of equipment failures and to repair only the nodes in pre-accident condition. Considering the import phase-out policy, the solution for this task will allow to adapt the SPR system to Russian market economy conditions and give the opportunity of commercial move by reducing the expenses for maintenance of Russian-made and imported equipment.
\end{abstract}

\section{Introduction}

At present Russian coal mining enterprises use the system of maintaining the technological equipment in the proper working order (SPR). The analysis of the SPR system and the underlying regulatory documentation allows to assert that the SPR system has not yet outlived its usefulness until now, but requires a new approach $[1,2]$.

The main guideline document that shall be subject to compulsory implementation for all coal mining enterprises of the USSR and then Russian Federation is the Regulation on scheduled preventive repair of the equipment used at open-cast mining works [2]. It was enacted in 1983, and remains valid through present and is applicable to: shovel excavators, drill rigs, transport and overburden bridges, stackers and overloaders, extensible belt conveyers and dredge pumps.

The matter of the SPR system is that after a certain number of machine hours and/or accomplished scope of work scheduled repair of different types is performed, and the sequence of repair must be defined due to component life and operating condition of the equipment. At the same time the Regulation presupposes improvement for SPR system by development and application of automated control systems of maintenance and repair, im-

\footnotetext{
* Corresponding author: mike.drygin@gmail.com
} 
proving repair technology and use of specific monitoring and metering instruments and means [2].

With the reference to the above mentioned it can be affirmed that the SPR system is based not only on the planned replacement of the equipment components after a certain number of running hours, but on the constant control of the technical state during the shift changeover and recording it to the "Shift turnover register", and planning of medium, normal and annual maintenance. Thus defect list which is an integral part of the SPR system is one of the most important documents, and it should be drafted correctly for the balance of the whole system.

Again, judging by the terminology of the Regulation, scheduled preventive repair is nothing but a system that requires long-term and short-term planning based on planned maintenance works with the schedule made up due to monitoring the technical condition of the equipment at any time in accordance with the defect list. The defect list is drafted by a qualified specialist, and the list of repair parts demanding age replacement is nothing short of long-term planning (including national scale) and partly error insurance for the specialist who drafts the defect list.

At the same time it is important to note that within the last ten years staff competence has dropped dramatically as well as the number of young and qualified workers among engineering control and top management. The result of intensification of production, globalization of economy and the above mentioned processes can be regarded as the factor that has determined inappropriate technical condition of coal mining equipment and excavators in particular.

\section{Materials and Methods}

Within the period since 2009 to 2013, the authors had performed more than three hundred complex diagnostic tests of the technical state of the excavators at Kuzbass open-cast coal mines. The extended diagram of these tests' result is presented on the Fig. 1. The diagram shows that only $14 \%$ of the excavating equipment is in good technical condition, and $27 \%$ is in unsatisfactory but still working condition.

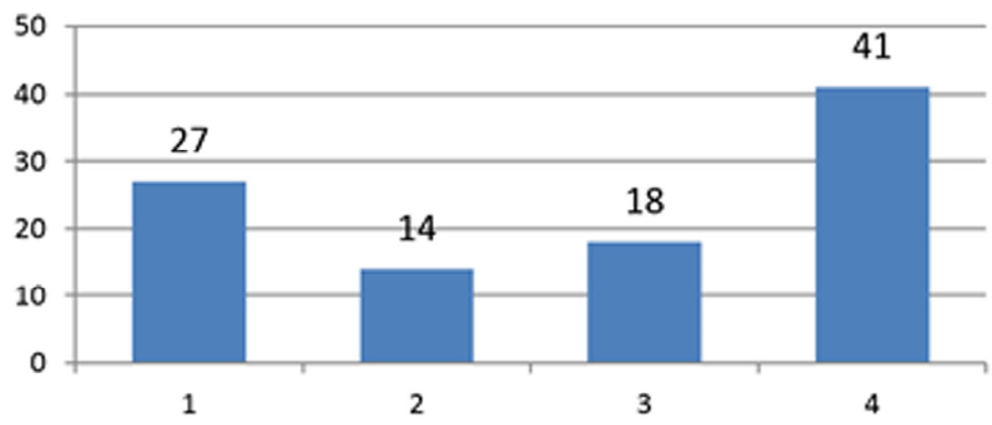

Fig. 1. Real situation of the excavating equipment at Kuzbass open-cast coal mines according to the results of diagnostic studies.

Methods used during the evaluation, such as vibration diagnostics, heat monitoring, visual and dimensional inspection, ultrasonic control, metal magnetic memory method, give a true and fair view of flaws distribution. When adequately interpreted these methods reveal a host of presented defects and an opportunity of system-oriented analysis of cause-and-effect relationship in their development $[4,5,6]$.

According to the analysis of the obtained results it can be asserted that the most important problem of retaining excavator fleet survivability is keeping constructional steel- 
work in good technical condition and avoiding its destruction [7]. According to the above mentioned Regulation on SPR basic methods of constructional steelwork control are visual and dimensional inspection and ultrasonic testing. Time allowance for ultrasonic testing of welded joints are also given in the Regulation (Table 1).

Table 1. Time allowance for ultrasonic flaw detection in welded metallic structures of excavators.

\begin{tabular}{|l|l|c|}
\hline \multicolumn{1}{|c|}{ Excavator type } & $\begin{array}{l}\text { Monitoring time, } \\
\text { days }\end{array}$ & $\begin{array}{l}\text { Number of welded } \\
\text { seams subject to } \\
\text { inspection, items. }\end{array}$ \\
\hline EKG-4,6b; EKG-5a & 4 & 26 \\
\hline EKG-8; EKG-6,3us; EKG-4u & 12 & 12 \\
\hline EKG-12,5; EKG-6,3u & 15 & 8 \\
\hline ESh-6/45 & 13 & 26 \\
\hline ESh-10/70 & 15 & - \\
\hline ESh-13/50 & 15 & 33 \\
\hline ESh-15/90 & 15 & - \\
\hline ESh-20/90 & 16 & 16 \\
\hline
\end{tabular}

Even without considering the basics of control process technology but only according to the data presented in Table 1 a conclusion can be made about significant efforts that ultrasonic control requires. For instance, the extension of 26 welding seams of Esh-10/70 mining shovel boom subject to ultrasonic control is $245,60 \mathrm{~mm}$. More than $294,000 \mathrm{~mm}$ of the whole boom are strength weld. Fig. 2 shows general view of the Esh-10/70 drag-line boom and allows to evaluate the amount of constructional steelwork that needs control. Constructional steelwork with shop weld that is subject to ultrasonic flaw detection. It is assumed that the rest of the welded seams will not fracture until the moment of disposal, taking into account all performed repairs including flaw detection (for instance, during the capital repair). Repair welded seams are also not subject to control and therefore remain "dangerous" [8].

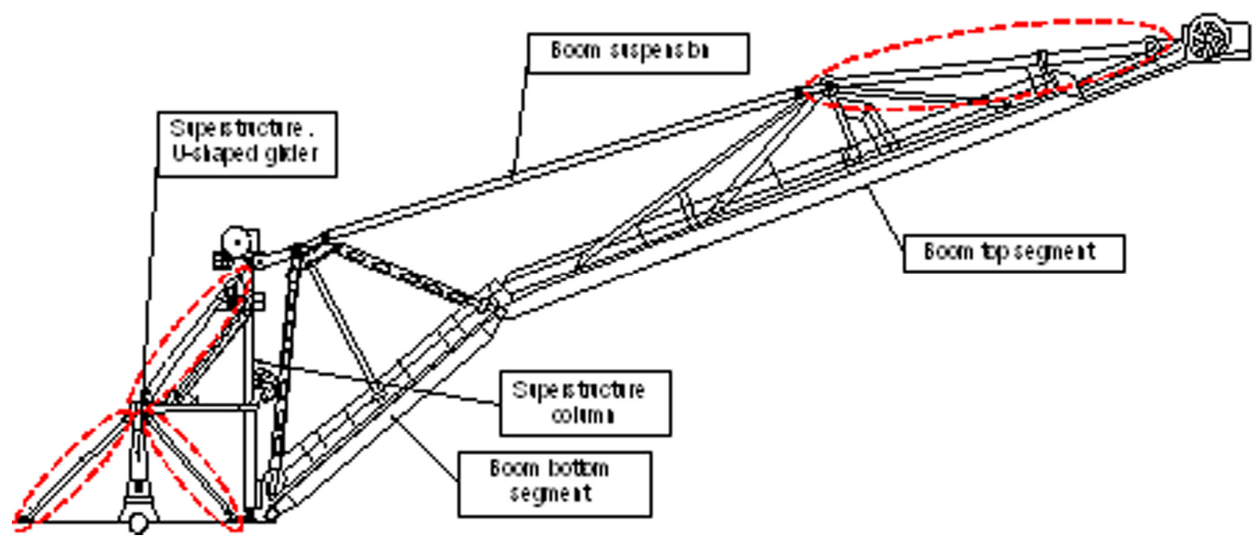

Fig. 2. General arrangement of a mining shovel Esh-10/70 boom.

Fatigue cracks developing from technological repair defects that were not detected during the control procedures performed after repair are the main reason of metallic structures' destruction. Fig. 3 shows a fracture of a mining shovel boom metallic structure along a basic metal crack that developed cyclically. Intolerable slag inclusions of a welded seam which is not subject to control in accordance with the Regulation, served as a concentrator $[9,10,11,12]$. 


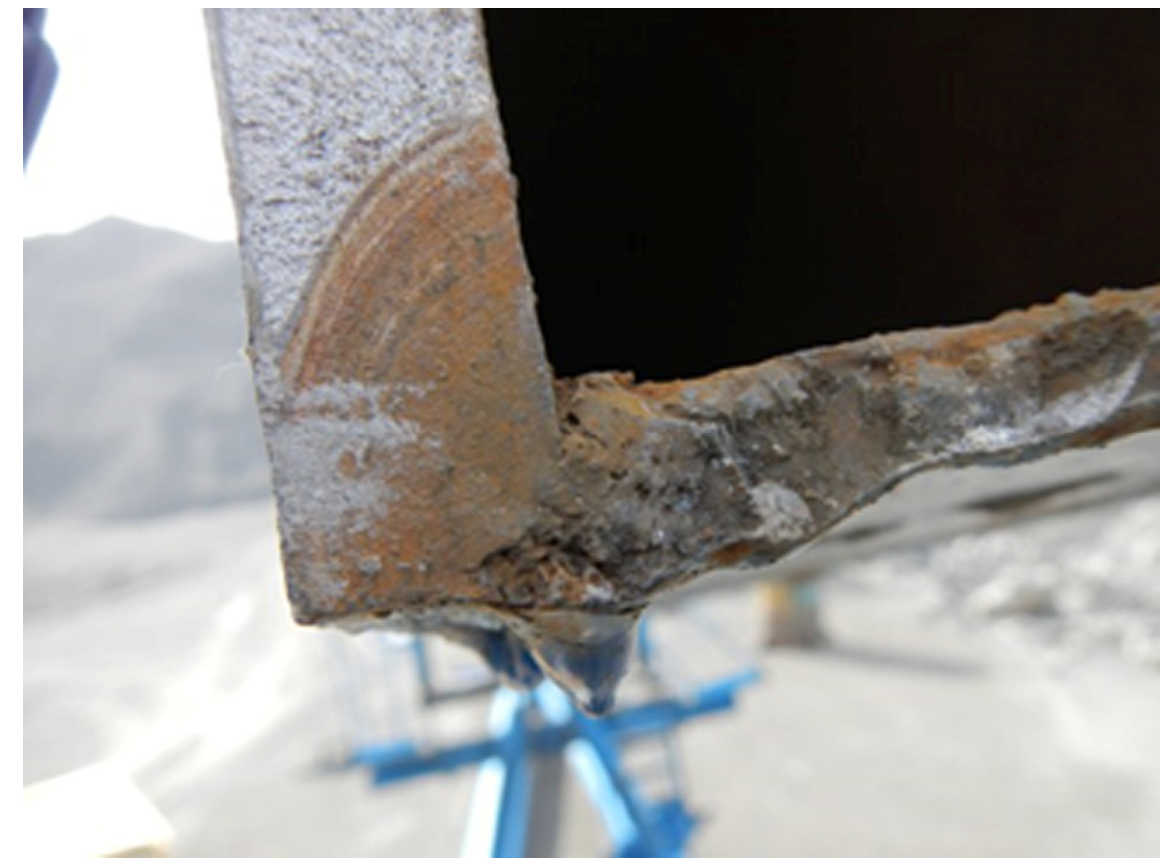

Fig. 3. Fracture of a mining shovel boom metallic structure.

After analyzing more than fifty similar metallic structures followed a conclusion that $100 \%$ welded seams should be subject to control, but that would require other, more highlyefficient control methods.

\section{Results and Discussion}

According to performed analytical and practical work a scheme of performing nondestructive testing procedures for metallic structures that had reached the end of their service life was worked out $[13,14]$. The first accepted method was visual and dimensional control. As one of basic control methods it allows to detect the most part of surface defects. Compared with other methods of non-destructive control visual and dimensional testing is highly-efficient and not expensive and allows the specialist to detect the most part of defects with minimum opening about $10 \mu \mathrm{m}$ [15]. However the main disadvantage of this method is human factor (fatigability, site preparation quality, physical well-being of the engineer performing the inspection) and absence of possibility to detect developing surface and all subsurface defects. The table of some non-destructive control methods' sensitivity evaluation data is given below (Table 2).

The second accepted method of $100 \%$ welded seams control was metal magnetic memory method. It is based on recording and analysis of diffusion self-magnetic fields that appear on the equipment metallic surface in stress concentration zones [16].

In comparison with other non-destructive control methods metal magnetic memory's main advantage is that it does not require any preparation of metal surface before inspection. Besides flaw detection metal magnetic memory method gives information about real state of the object and allows to find reasons of flaw development [17].

Table 2. Evaluation data of sensitivity of some non-destructive testing methods.

\begin{tabular}{|l|c|c|c|}
\hline \multirow{2}{*}{ Method } & \multicolumn{3}{|c|}{ Minimum size of detected discontinuity flaws, $\mu \mathrm{m}$} \\
\cline { 2 - 4 } & opening & extension & depth \\
\hline
\end{tabular}




\begin{tabular}{|l|c|c|c|}
\hline $\begin{array}{l}\text { Visual and optical con- } \\
\text { trol }\end{array}$ & $5 \ldots 10$ & 100 & - \\
\hline Dye-penetrant test & $1 \ldots 2$ & $100 \ldots 300$ & $10 \ldots 30$ \\
\hline $\begin{array}{l}\text { Fluorescent-penetrant } \\
\text { inspection }\end{array}$ & $1 \ldots 2$ & 100 & $10 \ldots 30$ \\
\hline $\begin{array}{l}\text { Magnetic particle meth- } \\
\text { od }\end{array}$ & 1 & 30 & $10 \ldots 50$ \\
\hline Eddy current method & $0.5 \ldots 1$ & 6 & $150 \ldots 2000$ \\
\hline Ultrasonic method & $0.01 \ldots 1$ & 10 & - \\
\hline Radiographic method & $100 \ldots 500$ & - & $1 \ldots 1.5$ \\
\hline
\end{tabular}

In support of this conclusion Fig. 4 shows the oscillogram of self-magnetic field stress of a weak weld of a Esh-10/70 drag-line boom head. The criteria of detected stress concentration zones' danger level is magnetic field intensity. Thus the level of $27.8(\mathrm{~A} / \mathrm{m}) / \mathrm{mm}$ is unacceptable - maximum point on the oscillogram below. This is confirmed by calculation of real magnetic deformation capacity index:

$$
m_{r}=\sqrt{\frac{k_{\max }}{k_{\mathrm{m}}}}=\sqrt{\frac{27.8}{3.7}}=2.74,
$$

where $k_{\max }$ is self-magnetic field maximum gradient; $k_{\mathrm{m}}$ is mean value of magnetic field gradient.

Extreme magnetic index characterizing metal deformation capacity:

$$
m_{\text {ext }}=\left(\frac{\sigma_{\mathrm{B}}}{\sigma_{\mathrm{T}}}\right)^{2}=\left(\frac{490}{350}\right)^{2}=1.96,
$$

where $\sigma_{\mathrm{B}}$ is metal endurance strength, $\mathrm{MPa} ; \sigma_{\mathrm{T}}$ is metal yield strength, $\mathrm{MPa}$.

Deformation index must not excess extreme index. In this case deformation index is 1.4 times more than extreme index. Therefore the section of a welded seam with a stress concentration zone is unfit for operation.

The form of the oscillogram is the third criterion supporting this conclusion. Specific distribution of magnetic field intensity is shown distinctly on the Fig. 4. In this case given the lateral (across the supposed defect) direction of the probe movement on the oscillogram specific distribution with fading-in, spike in and symmetrical descent of magnetic field gradient is formed.

This defect was confirmed during referee ultrasonic control as a subsurface discontinuity flaw with depth of location $2 \ldots 12 \mathrm{~mm}$, and this allowed to prevent a breakdown with boom head fracture because this welded seam was not mentioned in the "Reference Guide on Ultrasonic Flaw Detection of Single-bucket Excavators" as subject to traditional control.

Therefore complex approach to flaw detection of all welded seams in metallic structures allows to detect up to $100 \%$ of defects unacceptable according to regulatory documentation. The generalized result of such approach to the control of a metallic structure that was more than 20 years in operation with total length of welded seams up to 100 meters was the following: 

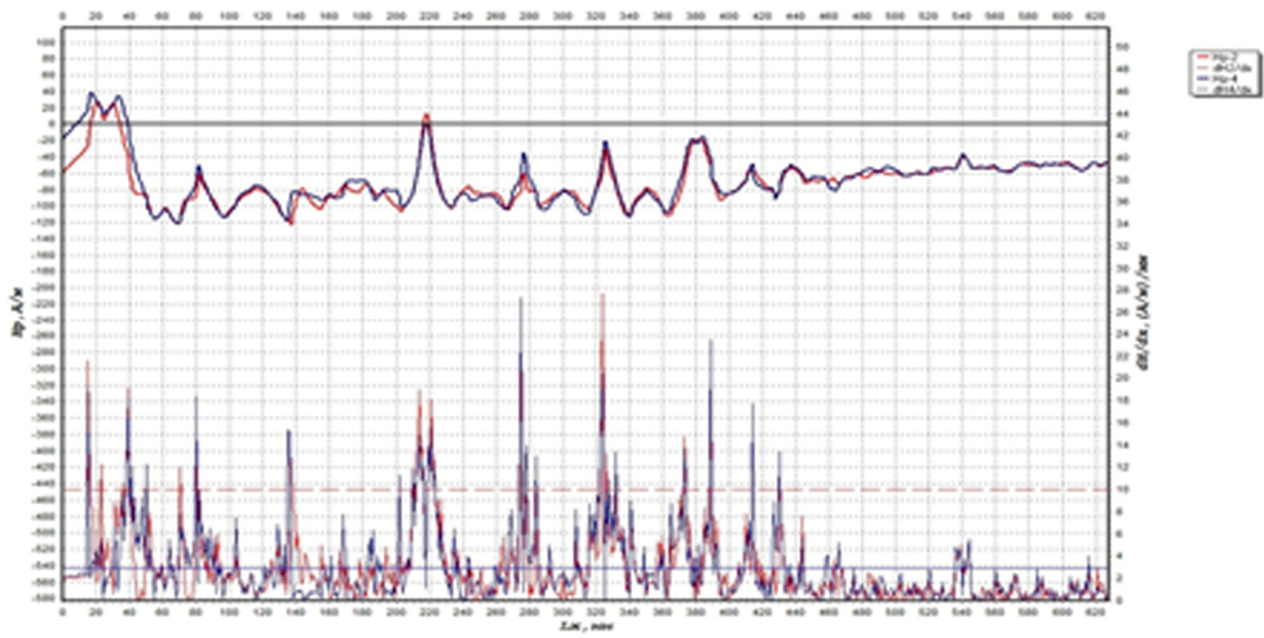

Fig. 4. Oscillogram of a weak weld magnetic field intensity.

- visual and dimensional testing allowed to detect about 40,000 mm of welded seams that are not in compliance with the regulatory documentation;

- metal magnetic memory method allowed to detect about 60,000 Mм of stress concentration zones where $12,800 \mathrm{~mm}$ of welded seams became critical and demanded subsequent operational supervision;

- Ultrasonic testing allowed to detect $4,500 \mathrm{~mm}$ of defects demanding immediate removal.

\section{Conclusion}

1. Improving efficiency and quality of mining equipment repair based on the system of scheduled preventive repair with wide use of non-destructive control methods and means allows in the short run to achieve good results characterized by reducing emergency downtime and proper repair.

2. The opportunity of using a host of non-destructive control methods and means within the SPR system is included into the regulatory documentation. Therefore implementation of one modern non-destructive control methods - metal magnetic memory - allows to solve one of the most important problems - flaw detection in significant amounts of welded joints of metallic structures within a short time.

3. Using the metal magnetic memory method allows to describe with high level of confidence the type of the defect and the level of its danger that will further allow to remove only dangerous defects, and this will provide efficiency of metallic structures over extended periods.

\section{References}

1. V. A. Kovalev, A. A. Khoreshok, O. I. Litvin, The 8th Russian-Chinese Symposium. Coal in the 21st Century: Mining, Processing and Safety, 287 (2016)

2. A. Morshedlou, H. Dehghani, S. H. Hoseinie, JME, 5:2, 113 (2014)

3. S. Namata, Performance analysis of heavy earth moving machineries (hemm) in opencast coal mines. Department of Mining Engineering, (Rourkela National Institute of Technology, 2015). 
4. E. Todorov, R. Spencer and M. Lozev, M. E., 72:6, 812 (2014)

5. L. De Chiffre, S. Carmignato, R. Kruth, J. P. Schmitt, Manuf. Technol., 63:2, pp. 655 (2014)

6. ISO 10042 Welding - Arc-welding joints in aluminium and its alloys - Quality levels for imperfections (2005)

7. ISO 3834-1 Quality requirements for fusion welding of metallic materials - Part 1: Criteria for the selection of the appropriate level of quality requirements (2005)

8. ISO 3834-2 Quality requirements for fusion welding of metallic materials - Part 2: Comprehensive quality requirement (2005)

9. ISO 3834-3 Quality requirements for fusion welding of metallic materials - Part 3: Standard quality requirements (2005)

10. ISO 3834-4 Quality requirements for fusion welding of metallic materials - Part 4: Elementary quality requirements (2005)

11. R. Talathi, Corporate planning: features, process and analysis / management. Your Article Library.

12. R. Gedrey, Stress-life fatigue testing basics. (Quality Magazine)

13. H. M. Kroening, D. Sednev \& Y. A. Salchak, Advanced Materials Research, 1040 (2014)

14. ISO 24497-3, Non-destructive testing - Metal magnetic memory - Part 3: Inspection ot welded joints (2009)

15. T. Nelligan, Ultrasonic flaw detection as a quality tool, (Berlin: Quality Magazine)

16. A. A. Dubov, Al. A. Dubov, and S. M. Kolokolnikov, Method of metal magnetic memory and inspection devices. Training handbook. 320 (Moscow: Tisso Co., 2003)

17. ISO 24497-2: Non-destructive testing - Metal magnetic memory - Part 2. General requirements (2007) 
